\title{
Ruminococcus bromii sp. n. and Emendation of the Description of Ruminococcus Sijpestein
}

\author{
W. E. C. MOORE, ELIZABETH P. CATO, and LILliAN V. HOLDEMAN \\ Anaerobe Laboratory, Virginia Polytechnic Institute and State University, Blacksburg, \\ Virginia 24061
}

\begin{abstract}
Ruminococcus bromii sp. $\mathrm{n}$. is described. It grows anaerobically, produces ethanol and acetic and formic acids from fermentable carbohydrates, and has complex nutritional requirements, indicating that it is a member of the genus Ruminococcus, which is here emended.
\end{abstract}

Ruminococcus bromii sp. $\mathrm{n}$. is a strictly anaerobic, gram-positive coccus which requires fermentable disaccharide, polysaccharide, or fructose for good growth. This species is one of the predominant species of the fecal flora of humans and hogs. The type strain is ATCC (American Type Culture Collection) 27255. The cultural characteristics and metabolic products of this species indicate that it is a member of the genus Ruminococcus, as emended, in that it produces acetic and formic acids from fermentable carbohydrates and has complex nutritional requirements.

\section{MATERIALS AND METHODS}

The fecal flora of two clinically healthy humans was cultured in the prereduced, anaerobically sterilized, rumen fluid-glucose-cellobiose agar (RGCA) of Bryant using the modifications and procedures described in reference 1. Colonies were picked from roll tubes without selection by subculturing each isolated colony starting from the top (of the roll tubes) until a predetermined number of isolates had been obtained. All isolates were characterized by procedures previously described (1).

The type strain of Peptococcus saccharolyticus (ATCC 14953) was examined by the same procedures.

\section{RESULTS}

The colony counts in roll tubes ranged between $6 \times 10^{10}$ and $3 \times 10^{11}$ per $\mathrm{g}$ (wet weight) of human feces and were equivalent (within the limits of accuracy of diluting and counting techniques) to the direct microscopic clump counts, thus indicating that the culture technique is nonselective and that most of the species were cultured in proportion to their occurrence in feces.

Of 495 isolates from one human fecal specimen, 94 (19\%) were the Ruminococcus species in question. Of 266 isolates from a fecal specimen of a second human, 24 (9.4\%) were the same species. We had previously isolated and characterized similar strains from feces of another human and of a hog; 124 strains were available for characterization.

Characterization. The organism is easily recognized by its poor growth in the absence of fructose, disaccharides, or polysaccharides; by its strong amylolytic activity; and by its production of ethanol, acetic, and formic acids as major products of carbohydrate fermentation.

Morphology. Cells are cocci, 0.7 to $1.1 \mu \mathrm{m}$ in diameter, occurring in pairs and in chains up to eight cells long (Fig. 1). Approximately half of the cells do not retain Gram stain after $24 \mathrm{hr}$ of incubation in media suitable for growth. They are nonmotile and have no flagella. Broth cultures are turbid, usually with slight sediment. Colonies on RGCA are 0.5 to $6 \mathrm{~mm}$ in diameter, circular, entire, convex, semi-opaque, whitish, and glistening.

Aerotolerance. The organism is strictly anaerobic and often fails to produce surface colonies when plates of freshly prepared media are exposed to air even briefly before inoculation and incubation in anaerobe jars. If growth is produced, colonies are punctiform. However, colonies are readily obtained on the surface of prereduced roll streaks that are kept anaerobic throughout inoculation and incubation.

Cultural and biochemical characteristics. Little or no growth is produced in peptone-yeast 
extract broth or in this basal medium with a nonfermentable carbohydrate. Carbohydrates fermented and other biochemical characteristics of the organism are given in Table 1 . The $p \mathrm{H}$ of

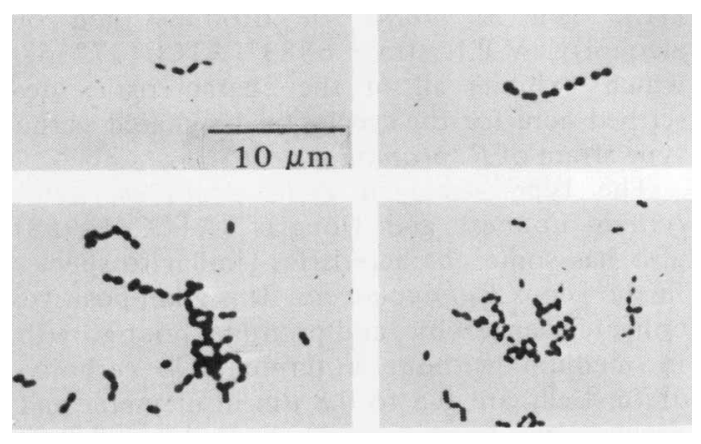

FIG. 1. Morphology of Ruminococcus bromii. Peptone-yeast extract, 3 days (upper left); glucose, $I$ day (upper right); maltose, 1 day (lower left); maltose, 3 days (lower right). cultures in broth with fermentable carbohydrate is 4.8 to 5.1 after $24 \mathrm{hr}$ of growth. Light turbidity and a $p \mathrm{H}$ of 5.7 to 5.9 (weak acid) are sometimes produced in glucose cultures after incubation for 24 to $48 \mathrm{hr}$. The strains uniformly hydrolyze starch. The ability of a strain to ferment carbohydrates depends on the culture used as inoculum. After freeze-drying or continued laboratory subculture, strains often lose their ability to produce acidity below $p \mathrm{H}$ 5.5 in starch (and sometimes in other carbohydrate broths) unless they are first transferred into medium containing rumen fluid. The per cent of the strains that ferment the various carbohydrates therefore will vary, depending on the kind of inoculum used. The species can be most easily recognized by its ability to hydrolyze starch and ferment maltose, its poor growth in medium without fermentable carbohydrate, and its formation of measurable amounts of acetic and formic acids and ethanol as products of metabolism.

TABLE 1. Characteristics of species in the genus Ruminococcus and of Peptococcus saccharolyticus ${ }^{a}$

\begin{tabular}{|c|c|c|c|c|c|}
\hline \multirow[b]{2}{*}{$\begin{array}{l}\text { Substrate } \\
\text { or } \\
\text { reaction }\end{array}$} & \multicolumn{5}{|c|}{ Species $^{b}$} \\
\hline & R. flavefaciens ${ }^{c}$ & $R$. albus $s^{d}$ & $\begin{array}{c}P . \text { saccharolyticus } \\
\text { type strain } \\
\text { ATCC } 14953\end{array}$ & R. bromii & $\begin{array}{c}R . \text { bromii } \\
\text { type strain } \\
\text { ATCC } 27255\end{array}$ \\
\hline Arabinose $\ldots \ldots \ldots$ & - & $-^{\mathbf{a}}$ & - & - & - \\
\hline Cellobiose . . . . . . & $a^{w}$ & $a^{w}$ & - & - & - \\
\hline Esculin $(p \mathrm{H}) \ldots \ldots$ & $-a$ & - & - & - & - \\
\hline Fructose $\ldots \ldots \ldots$ & - & $-\mathbf{a}$ & $\mathrm{a}$ & $a^{-}$ & $\mathbf{a}$ \\
\hline Galactose $\ldots \ldots \ldots$ & - & - & - & $a^{-}$ & a \\
\hline Glucose $\ldots \ldots \ldots \ldots$ & $-{ }^{a}$ & $-^{\mathbf{a}}$ & $\mathrm{a}$ & $\bar{w}$ & $\mathrm{w}$ \\
\hline Glycerol $\ldots \ldots \ldots$ & - & - & $\mathrm{a}$ & - & - \\
\hline Glycogen $\ldots \ldots \ldots$ & . & & - & $a^{-}$ & - \\
\hline Lactose . . . . . . . & $-{ }^{\mathbf{a}}$ & $-{ }^{a}$ & - & - & - \\
\hline Maltose $\ldots \ldots \ldots \ldots$ & - & -- & - & $a^{w}$ & $\mathbf{a}$ \\
\hline Mannose $\ldots \ldots \ldots$ & - & $-{ }^{\mathbf{a}}$ & w & $-\mathbf{w}$ & - \\
\hline Melibiose . . . . . . . & & & - & $-{ }^{a}$ & - \\
\hline $\operatorname{Starch}(p \mathrm{H}) \ldots \ldots \ldots$ & - & - & - & $a^{-}$ & a \\
\hline Starch (hydrolysis) ... & - & - & - & + & + \\
\hline Sucrose $\ldots \ldots \ldots \ldots$ & $-\mathbf{a}$ & $-{ }^{a}$ & - & - & - \\
\hline Xylose $\ldots \ldots \ldots \ldots$ & $-^{a}$ & - & - & - & - \\
\hline Gelatin digestion ..... & - & $--^{+}$ & - & - & - \\
\hline Catalase .......... & - & - & + & - & - \\
\hline Products of fermentation ${ }^{e}$ & $\operatorname{ASF}(1)$ & A (fls) 2 & FA (iv) & a (flp) 2 & aflp $2^{c, d}$ \\
\hline
\end{tabular}

${ }^{a}$ All species: inulin, mannitol, raffinose, rhamnose, salicin, and trehalose not fermented; nitrate, not reduced indole, not produced. $R$. bromii and $P$. saccharolyticus, in addition, did not ferment adonitol, amygdalin, dulcitol, ery thritol, inositol, melezitose, ribose, sorbitol, and sorbose; esculin, not hydrolyzed; milk, not changed: meat, not digested; lecithinase and lipase, not produced.

${ }^{b}$ Symbols: - = no growth, negative reaction, or $p \mathrm{H}$ above $6.0 ; \mathrm{w}=p \mathrm{H} 5.5$ to $6.0 ;(\mathrm{a})=p \mathrm{H}$ below $5.5 ;+=$ positive reaction; superscripts $=$ results from a minority of the strains examined.

c Characteristics cited from Bryant (2), Hungate (4), and Rogosa (personal communication).

$d$ Milliequivalents per $100 \mathrm{ml}$ from maltose broth culture $=1.25$ acetic acid, 1 formic acid, 0.15 lactic acid, and 0.05 propionic acid.

${ }^{e} \mathrm{~A}=$ acetic acid; $\mathrm{S}=$ succinic acid; $\mathrm{F}=$ formic acid; 2 = ethanol; iv = isovaleric acid; $\mathrm{p}=$ proponic acid; lower case letters $=<1 \mathrm{meq} / 100 \mathrm{ml}$; parentheses indicate variable production. 


\section{DISCUSSION}

To our knowledge, no species of anaerobic coccus with these distinctive characteristics has been named previously. This probably is the same organism as "bacterial group 10" isolated from human feces by Eller et al. (3) where it represented 9 to $14 \%$ of the total bacteria isolated from the fecal samples studied. The strains in bacterial group 10 hydrolyze starch. The production of little or no growth in glucose medium and the rather strict anaerobic nature of this organism may explain why it has not been reported until recently, even though it often forms an important part of the predominant normal fecal flora of humans. After reviewing our previous data on "unidentified" strains that we had isolated from other humans and from hogs, we found five strains from feces of one hog and at least one strain from feces of another human that belong to this species. Actual incidence of this species in these specimens is difficult to estimate because of the small number of colonies picked and our previous reliance on glucose for subculture from rumen fluid medium (1) cultures.

The strains of this species are more like those of the genus Ruminococcus as described by Rogosa (5) than like those of the genus Peptostreptococcus (5). Strains are similar to those of $R$. albus and $R$. flavefaciens in that they have similar products of fermentation, they regain their ability to ferment carbohydrates after transfer in medium containing rumen fluid, and they grow poorly, if at all, in medium not containing a fermentable carbohydrate. The type strain of $R$. bromii, analyzed by J. L. Johnson, has a guanine plus cy tosine (GC) content of 39 to 40 moles $\%$ by $\mathrm{Tm}$. This compares with values of 39.8 to 45.4 moles \%GC reported for the genus (5). Strains of $R$. bromii differ from the new description of Ruminococcus (5) in specific characteristics (e.g., starch hydrolysis and cellobiose fermentation). We do not feel that variation in these characteristics should exclude this species from the gerus Ruminococcus and therefore propose the following emended description for Ruminococcus:

Ruminococcus Sijpestein 1948.

Spherical to somewhat elongated coccoid cells which occur singly, in pairs, or in short chains. Gram-positive but decolorize easily. Anaerobic chemoorganotrophs which have complex nutritional requirements. Most strains grow poorly, if at all, in medium without a fermentable carbohydrate, and a fermentable carbohydrate is usually required for continued subculture. Major products from carbohydrate fermentation are acetic and formic acids with or without succinic acid or ethanol, or both.

Type species: $R$. flavefaciens.

For the 124 strains isolated from feces, we propose the name Ruminococcus bromii sp. $\mathrm{n}$. [M.L. gen n. bromii of Bromius (god of alcohol)]. V.P.I. strain 6883 (ATCC 27255), which exhibits all of the characteristics described here for the species, is designated as the type strain of $R$. bromii.

The type strain of Peptococcus saccharolyticus Foubert and Douglas (ATCC 14953) also has some characteristics similar to species in the genus Ruminococcus. It is gram-positive, obligately anaerobic, and produces poor growth in medium without a fermentable carbohydrate. Cells are 0.5 to $0.8 \mu \mathrm{m}$ in diameter and occur singly, in pairs, or in short chains. Major fermentation acids are acetic $(2 \mathrm{meq} / 100 \mathrm{ml})$ and formic $(6 \mathrm{meq} / 100 \mathrm{ml})$ in peptone-yeast extract-glucose cultures. However, the GC content of the deoxyribonucleic acid (DNA) as deterrinined by J. L. Johnson using Tm is 30 to 31 moles \%. The DNA preparation contained some pigment that may have decreased the value of the result, but we do not propose to transfer this species to the genus Ruminococcus because the observed value is close to the 33.5 moles \% reported for Peptostreptococcus species (5).

\section{ACKNOWLEDGMENTS}

We thank Linda S. Knight and Dale D. Charles for their assistance. This investigation was supported by Public Health Service Grant GM-14604 from the National Institute of General Medical Sciences and contract 71-2427 from the National Cancer Institute.

\section{LITERATURE CITED}

1. Anaerobe Laboratory. 1970. Outline of clinical methods in anaerobic bacteriology, 2nd revision. Virginia Polytechnic Institute and State University, Blacksburg, Va.

2. Bryant, M. P., N. Small, C. Bouma, and I. M. Robinson. 1958. Characteristics of ruminal anaerobic celluloytic cocci and Cillobacterium cellulosolvens n. sp. J. Bacteriol. 76:529-537.

3. Eller, C., M. R. Crabill, and M P. Bryant. 1971. Anaerobic roll tube method for nonselective enumeration and isolation of bacteria in human feces. Appl. Microbiol. 22:522-529.

4. Hungate, R. E. 1957. Microorganisms in the rumen of cattle fed a constant ration. Can. J. Microbiol. 3:290-311.

5. Rogosa, M. 1971. Peptococcaceae, a new family to include the gram-positive, anaerobic cocci of the genera Peptococcus, Peptostreptococcus, and Ruminococcus. Int. J. Syst. Bacteriol. 21:234-237. 